\title{
Panniculitis in the newborn: a case report
}

\author{
Paniculite no recém-nascido: relato de um caso
}

Fernando Bastos ${ }^{1}$, Liliana Thaureaux Pérez², Caridad Ponce de León Narváes², Olívia Costa² ${ }^{2}$ Maria Ódia Inácio de Sousa e Silva ${ }^{2}$, Rui Carlos Souto da Silva ${ }^{3}$, Joaquim Carlos Vicente Dias Van-Dunem ${ }^{4}$, Sandra Maria da Rocha Neto de Miranda $^{5}$, Lemuel Bornelli Cordeiro ${ }^{4}$, Tininha Ernesto Tembo ${ }^{2}$, Rosa Vinene de Almeida ${ }^{6}$, Ana Maria Vaz da Conceição ${ }^{7}$

\section{ABSTRACT}

The authors present a case of panniculitis in a newborn, a rare disease in the neonatal period discussing its causes and differential diagnosis, emphasizing a possible diagnosis of erythema nodosum.

Keywords: Panniculitis; Erythema nodosum; Infant, newborn; Case reports

\section{RESUMO}

Os autores apresentam um caso clínico de paniculite no recémnascido, uma afecção rara no período neonatal, discutindo prováveis causas e diagnóstico diferencial, dando ênfase ao possível diagnóstico de eritema nodoso.

Descritores: Paniculite; Eritema nodoso; Recém-nascido; Relatos de casos

\section{INTRODUCTION}

Panniculitis is an inflammatory process of cellular subcutaneous tissues. It could be primary or secondary as a reaction induced by systemic processes.

Some types of panniculitis, such as erythema nodosum, subcutaneous fat necrosis of newborn, sclerema neonatorum, and cold panniculitis appear only in children ${ }^{(1)}$.

Erythema nodosum (EN) is an inflammatory process of cellular subcutaneous tissues developed because of hypersensitivity to antigens. It usually appears in concomitance with several diseases, including infectious processes (like tuberculosis, leprosy, Chagas' disease, streptococcus infection, among other), sarcoidosis, rheumatologic disease, autoimmune disorders, malignant disease and due to drug action or pregnancy ${ }^{(2-5)}$.

In developed countries streptococcus infection and sarcoidosis are the most common cause of EN, particularly because cases of tuberculosis, Chagas' disease and leprosy are not so frequent, unlike developing countries ${ }^{()}$.

This disease affects women three to six times more than $\operatorname{men}^{(7-9)}$. Before puberty there is no predilection for gender. EN affects all races and it seems to occur in urban and rural areas without difference in incidence( ${ }^{(9)}$.

Clinically, EN lesions are painful and symmetrically distributed on lower limbs and might occur in the trunk $^{(4,9,10)}$. It has spontaneous resolution within 3 to 6 weeks from the beginning of the edema without leaving scars or atrophy of the skin ${ }^{(5)}$.

Diagnosis based only on clinical picture should be done carefully, a better practice is to corroborate it with histopathological findings from skin and subcutaneous biopsy that will allow a differential diagnosis with other diseases which may have a similar clinical picture ${ }^{(5,10,11)}$.

Preferable treatment must be done with administration of nonsteroidal anti-inflammatory drugs because EN has benign characteristics and corticosteroids might represent a factor for dissemination of infection ${ }^{(4)}$.

Subcutaneous fat necrosis of the newborn is usually found in the first weeks of life in full term newborns who have suffered an obstetric trauma.

\footnotetext{
${ }^{1}$ Neonatology Service of the Clínica Girassol - Luanda, Angola.

${ }^{2}$ Intensive Care Unit, Clínica Girassol - Luanda, Angola.

${ }^{3}$ Pediatric Surgery Service, Clínica Girassol - Luanda, Angola.

${ }^{4}$ Education and Research Desk, Clínica Girassol - Luanda, Angola.

${ }^{5}$ Epidemiology Service, Clínica Girassol - Luanda, Angola.

${ }^{6}$ Dermatology and Surgical Dermatology Service, Clínica Girassol - Luanda, Angola.

7 Diagnostic and Therapeutic Service of the Clínica Girassol - Luanda, Angola.

Corresponding author: Fernando Bastos - Rua Minas Gerais, 180 - CEP 122307-060 - Jacareí (SP) - Brazil - Tel.: (11) 3955-3444 - E-mail: fernandobbastos@yahoo.com.br

Received on: May 3, 2011 - Accepted on: Nov 1, 2011
} 
This disorder incidence is not completely known, and it has been reported in newborns born by forceps, suffering from perinatal anoxia or cooling, and may be due to maternal risk factors such as gestational diabetes, dyslipidemia, preeclampsia, hypertension, use of cocaine, smoking, use of calcium channelblocker in pregnancy, and maternal thrombosis. The disorder main complication is hypercalcemia and if not properly treated may lead to death $^{(12-14)}$. Other complications include hypoglycemia, thrombocytopenia and hypertriglyceridemia ${ }^{(14)}$.

Sclerema neonatorum affects premature newborns, and is characterized by rapid and generalized skin induration with a mortality rate of $75 \%(14,15)$.

Cold panniculitis appears when the newborn is exposed to cold. This affection is found in full term newborns, and appears as nodules in the area exposed to cold. It is a benign condition and resolves without complications ${ }^{(15,16)}$.

\section{CASE DESCRIPTION}

A male black infant, 2,640 g, 39 weeks of gestational age, was delivery by cesarean section because of cord encirclement, under intravenous general anesthesia at Girassol Clinic, in Luanda, Angola. His mother did not have adverse events during prenatal, and she did not report family diseases. In the delivery room the newborn had low Apgar score (1-minute: 1; 5-minutes: 5, and 10 minutes: 7) being submitted to resuscitation maneuvers. The infant was manually ventilated, and bronchial wash and aspiration was done, which revealed a large amount of meconium. His mucosae appeared well colored, and he was transferred to the neonatal intensive care unit and placed on assist-control mechanical ventilation. The child's skin was meconium stained. After 2 hours of mechanical ventilation there was an improve in the respiratory pattern, oxygen saturation and reduction in the fraction of inspired oxygen $\left(\mathrm{FiO}_{2}\right)$, which started in $100 \%$ and it fell to $50 \%$ when invasive mechanical ventilation was suspended. The newborn was then extubated. CPAP was started with $\mathrm{FiO}_{2}$ of $40 \%$ which provided comfort and efficacy to the patient's spontaneous ventilation. Two days later an edema was observed in newborn's dorsum at the occipital area, shoulders and thoracolumbar region reaching lower limbs up to the calcaneus and plantar region. In his face the same edema pattern was also observed, however, it was not observed on his body anterior region. The edema was indurate, smooth, resembling an "armor plating" with intense presence of cellulitis and nodules lighter than the normal skin around it (Figures 1 to 3). The laboratorial tests revealed serum calcium dosage of $2.0 \mathrm{mMol}$ in the first week of life, 2.15 $\mathrm{mMol}$ in the second week, $2.10 \mathrm{mMol}$ before hospital discharge. The glucose level was always above $70 \mathrm{mg} / \mathrm{dL}$ and blood count was normal for his age. The biopsy of the skin and subcutaneous cell tissue confirmed the diagnosis of septal panniculitis compatible with EN (Figures 4 and 5). After, possible etiologies for this condition were investigated. Streptococcal infection and the possibility of tuberculosis were the major suggestions, particularly because streptococcal infection is indicated by literature as the main factor to cause $\mathrm{EN}$, and tuberculosis constitutes an endemic disease in the country.

His mother was submitted to exams to exclude congenital tuberculosis transmitted through the birth canal. Two abscess on the shoulder and on the face became fluctuant and the drainage material was forwarded to microbiology analysis, which showed Streptococcus sp. The Mantoux test performed before BCG vaccine was done did not show any reaction to Koch's bacillus. The newborn had good response to the treatment using crystalline penicillin, dose of $50 \mathrm{mg} / \mathrm{kg}$ every four hours. He was discharged after 21 days of life, the lesions being improved gradually. We observed in a follow up at outpatient unit that injuries healed completely.

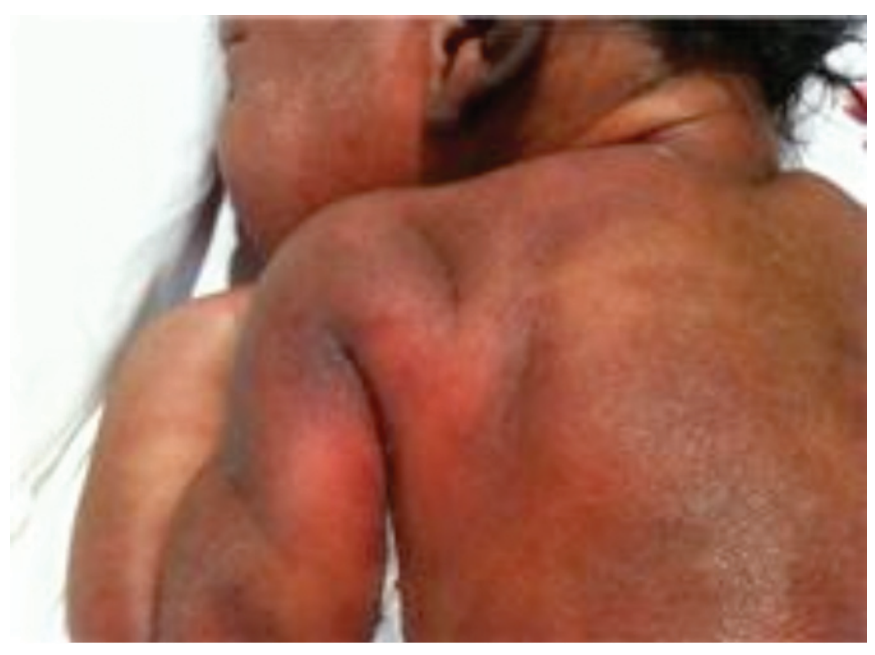

Figure 1. Injuries in newborn's arm and shoulder

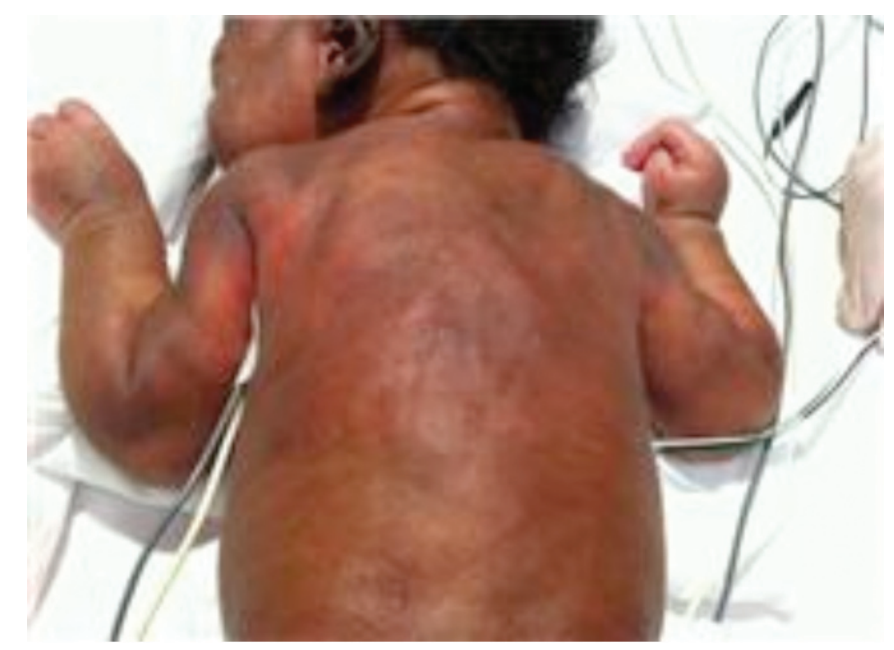

Figure 2. Injuries in newborn's dorsal region 


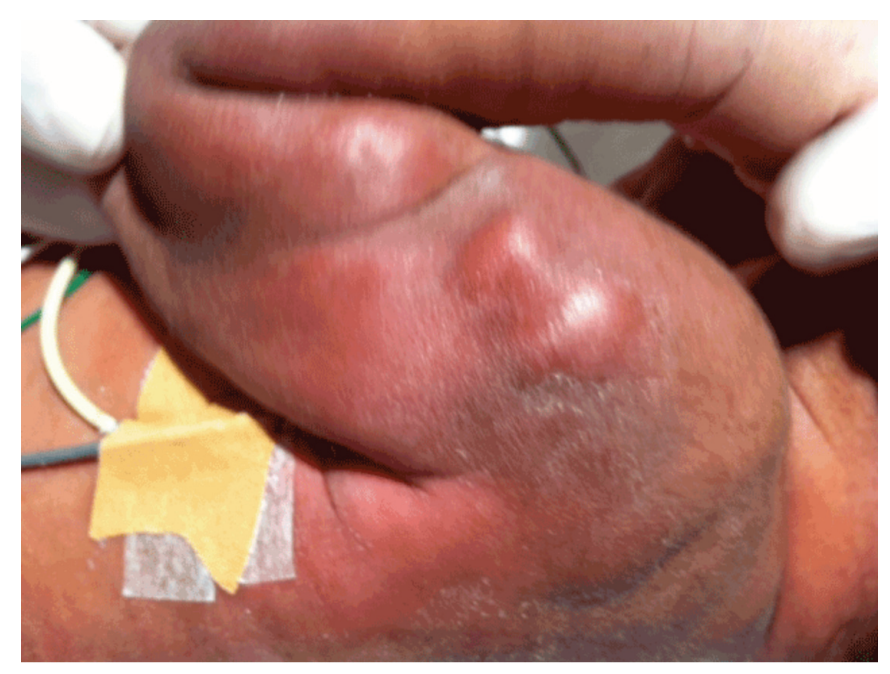

Figure 3. Injuries in newbon's arm

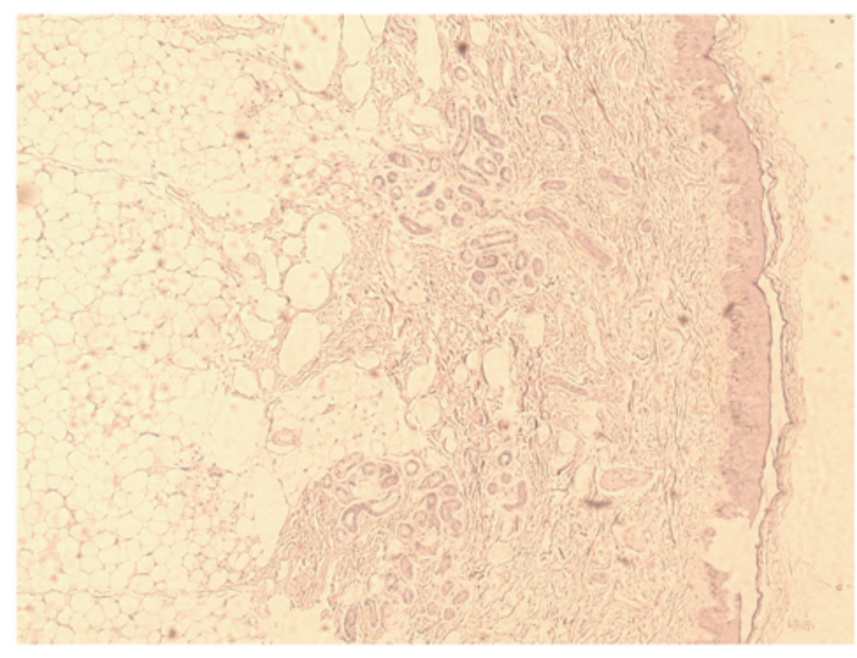

Figure 4. Microscopy of injuries of the newborn - fragment of skin of the shoulder

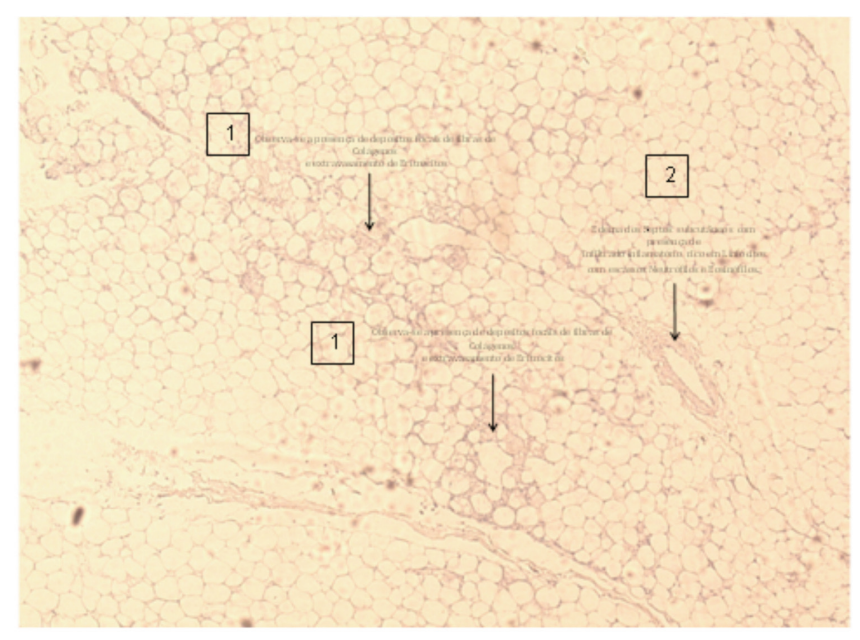

Figure 5. Focal collagen fibers storage and extravasation of erythrocytes (1). Subcutaneous septal edema with inflammatory infiltration (2)

\section{DISCUSSION}

Panniculitis is considered a rare entity throughout the neonatal period ${ }^{(9)}$. In this case report the subcutaneous erythematous nodules appearance, even in an atypical site, suggested the disease.

Despite, the biopsy was necessary to define the diagnosis of EN, and to confirm the presence of septal edema, inflammatory infiltration with predominance of lymphocytes, small number of neutrophils and eosinophils, extravasation of erythrocytes, and focal collagen fibers storage.

Although, Miescher's nodules that constitutes markers for this disease, were not identified, but sometimes cannot be found, requiring serial slice studies ${ }^{(9)}$.

Classically, tuberculosis infection has been described as the most frequent agent to cause this process particularly in children ${ }^{(11)}$. The etiology hypotheses in this case is debatable. In regions where tuberculosis has virtually been eliminated, the most common agent is beta-hemolytic streptococci ${ }^{(17-19)}$. The streptococci found in the drainage material from the nodules in this case could be only a secondary contamination, because EN is a delayed hypersensibility reaction without germs $\mathrm{s}^{(5)}$.

Because the newborn had perinatal asphyxia the main differential diagnosis to be done was with subcutaneous fat necrosis. Although this disease appears after one week of life, and presents hypercalcemia, histology has different characteristics and healing of the disease may be very slow taking several weeks or months ${ }^{(15)}$.

We excluded the diagnosis of subcutaneous fat necrosis because the panniculitis was predominantly septal with vasculitis, did not present fat necrosis and hypercalcemia was absent.

Other disease that might be considered would be cold panniculitis, but we did not find clinical reasons to confirm this hypothesis ${ }^{(15,16)}$. Another affection, sclerema neonatorum, is an acute disease usually found in premature newborns, thus this diagnosis was also excluded ${ }^{(15)}$.

This case was treated with antibiotic therapy and interventions according to the literature ${ }^{(1,9,10)}$.

This case diagnosed as EN in a newborn, a rare disease in the neonatal period, emphasizes the importance of a histological diagnosis for a definitive diagnosis.

\section{REFERENCES}

1. Polcari IC, Stein SL. Panniculitis in childhood. Dermatol Ther. 2010; 23(4):356-67

2. Fernandes NC, Macieira J, Muniz MM. Erythema nodosum: prospective study of 32 cases. Rev Inst Med Trop. 1994;36(6):507-13.

3. Centers for Disease Control and Prevention (CDC). Outbreak of erythema nodosum of unknown cause - New Mexico, November 2007-January 2008. MMWR Morb Mortal Wkly Rep. 2009;58(48):1347-51. 
4. Requena L, Yus ES. Erythema nodosum. Semin Cutan Med Surg. 2007;26(2):114-25.

5. Yi SW, Kim EH, Kang HY, Kim YC, Lee ES. Erythema nodosum: clinicopathologic correlations and their use in differential diagnosis. Yonsei Med $\mathrm{J}$. 2007:48(4):601-8.

6. Schwartz RA, Nervi SJ. Erythema nodosum: a sign of systemic disease. Am Fam Physician. 2007;75(5):695-700.

7. Tay YK. Erythema nodosum in Singapore. Clin Exp Dermatol. 2000;25(5):377-80.

8. Cribier B, Caille A, Heid E, Grosshans E. Erythema nodosum and associated diseases. A study of 129 cases. Int J Dermatol. 1998;37(9):667-72.

9. Requena L, Requena C. Erythema nodosum. Dermatol Online J. 2002;8(1):4. Review.

10. Sota Busselo I, Oñate Vergara E, Pérez-Yarza EG, López Palma F, Ruiz Benito A, Albisu Andrade Y. [Erythema nodosum: etiological changes in the last two decades]. An Pediatr (Barc). 2004;61(5):403-7. Spanish.

11. Torrelo A, Hernández A. Panniculitis in children. Dermatol Clin. 2008;26(4):491500 , vii. Review.

12. Mahé E, Girszyn N, Hadj-Rabia S, Bodemer C, Hamel-Teillac D, De Prost Y. Subcutaneous fat necrosis of the newborn: a systematic evaluation of risk factors, clinical manifestations, complications and outcome of 16 children. $\mathrm{Br}$ J Dermatol. 2007;156(4):709-15.

13. Aljaser F, Weinstein M. A 1-week-old newborn with hypercalcemia and palpable nodules: subcutaneous fat necrosis. CMAJ. 2008;178(13):1653-4.

14.Zhou W, Wiesenthal A, Carr V, Allison A, Kelly B, Gibson B. A firm plaque on the back of a newborn. Dermatol Online J. 2010;16(2):11.

15. Gómez-Fernández C, Feito Rodríguez M, Collantes Bellido E, Ybarra Zabala $\mathrm{M}$, de Lucas Laguna R. [Indurated plaque on the back of a newborn after undergoing whole-body cooling]. An Pediatr (Barc). 2011;74(1):64-6. Spanish.

16. Quesada-Cortés A, Campos-Muñoz L, Díaz-Díaz RM, Casado-Jiménez M. Cold panniculitis. Dermatol Clin. 2008;26(4):485-9, vii.

17. Labbe L, Perel Y, Maleville J, Taieb A. Erythema nodosum in children: A study of 27 patients. Pediatr Dermatol. 1996;13(6):447-50.

18. Garty BZ, Poznanski O. Erythema nodosum in Israeli children. Isr Med Assoc J. 2000;2(2):145-6.

19. Kakourou T, Drosatou P, Psychou F, Aroni K, Nicolaidou P. Erythema nodosum in children: a prospective study. Am Acad Dermatol. 2001;44(1):17-21. 